\title{
Niccolo Machiaveldi: MORALISTA OU INTELECTUAL ORGÂNICO?
}

\section{Vivian Matias dos Santos ${ }^{1}$}

\begin{abstract}
Resumo
Este artigo visa compreender o cerne do pensamento político de Maquiavel: o agir político por excelência. Ele inaugura em sua época uma maneira revolucionária de pensar a política, atacando o núcleo da moral cristã, e retomando a ética dos povos antigos. Aceitar os valores antigos significa apontar para uma ação política pautada no caráter público e coletivo. Sua obra abaliza uma ação política capaz de construir uma nova Itália: unificada e soberana. Argumentando contra a hegemonia da Igreja, primava pela emergência de um novo Bloco Histórico, o que lhe classificou antes de qualquer coisa, como um intelectual orgânico de seu tempo.

Palavras-chave: Política. Ética. Intelectual Orgânico.
\end{abstract}

\begin{abstract}
This article seeks to understand the core of Machiavelli's political thought: political action. He inaugurates in his era a revolutionary form of thinking about politics, attacking the nucleus of Christian morality, and returning to the ethics of ancient peoples. Accepting ancient values means promoting political action guided by

\footnotetext{
${ }^{1}$ Mestra em Políticas Públicas e Sociedade, Pesquisadora do grupo Gênero, Família e Geração nas Políticas Sociais e professora do curso de Serviço Social da Universidade Estadual do Ceará e das Faculdades INTA.E-mail: vivianmsa@yahoo.com.br.
} 
public and collective interests. His work defends a brand of political action capable of constructing a new Italy, unified and sovereign. Arguing against the hegemony of the church, he defended the construction of a new historical bloc, which classified him as an organic intellectual of his time.

Keywords: Politics. Ethics. Organic Intellectual.

\section{O PrínCiPe de Maquiavel: um “MANifesto Político”}

Criou-se o hábito de considerar Maquiavel, de modo excessivo, como o "político em geral", como o "cientista da política", atual em todos os tempos. É necessário considerar Maquiavel, em grau maior, como expressão necessária de seu tempo e como estreitamente ligado às condições e às exigências de sua época (...) (Gramsci, 2000, p. 29).

No século XVI, quando viveu Nicolau Maquiavel (1469-1527), a Itália vivenciava um prolixo momento político. A península estava dividida como uma "colcha de retalhos", na qual cada pequeno território possuía vida política, econômica e cultural distintas. 0 mapa político italiano era constituído por uma série de "cidades-livres" que conviviam com os Estados papais controlados diretamente pela Igreja, configurando-se da seguinte forma: ao Sul, havia o reino de Nápoles; os Estados pontifícios controlados pela Igreja e a república de Florença presidida pelos Médicis, no centro; ao Norte o ducado de Milão e a república de Veneza.

A Itália contemporânea de Maquiavel era, então, dividida em vários territórios que possuíam as mais diversas formas de governo. Muitos deles eram repúblicas controladas por cidades comerciais que adquiriram bastante importância, como por exemplo, Gênova e Veneza. Neste contexto a figura do papa assumia o papel de "rei feudal controlando terras e súditos, fazendo leis, comandando exércitos e se metendo em guerras" (SCHMIDT, 1996, p. 20).

Algumas das "cidades-estados" italianas eram rivais na economia e na política, assim eram constantes os conflitos. Tal conjuntura política de fragmentação einstabilidade-cujagrande influênciae controle eram estabelecidos predominantemente pela Igreja Católica - significou uma espécie de convite para 
que Maquiavel em suas obras argumentasse em torno da fundação e manutenção de um Estado unificado e forte.

Por vezes, o escrito de Maquiavel é taxado e reduzido a mero manual de exaltação do absolutismo. Todavia, de acordo com Gramsci, sendo o pensador um homem inteiramente de seu tempo, sua ciência política representou a filosofia de sua época que tendia para as monarquias nacionais absolutas, as quais naquele momento significavam o rompimento com a estagnação e o conseqüente desenvolvimento das forças produtivas burguesas. É necessário perceber que a ferocidade maquiaveliana "está voltada contra os resíduos do mundo feudal, não contra as classes progressistas" (2000, p. 30).

Suas obras, de acordo com Moreira (1980, p.12), refletem o ethos do Renascimento, época em que a visão de mundo medieval (teocêntrica), vai sendo substituída pelo antropocentrismo. Existia uma constante luta entre duas filosofias: a escolástica, encabeçada por Tomás de Aquino através de uma adaptação do pensamento Aristotélico; e a humanista, de acordo com a qual a razão não estava mais a serviço da fé, agora a Igreja se restringia à religião e a razão se ocupava do mundo, inclusive da política.

A filosofia renascentista procurava substituir o transcendentalismo medieval pela visão imanentista do mundo (SCHMIDT, 1996, p. 49). Ou seja, o conhecimento passa a ser buscado na própria realidade. Assim, foi contrariando a hegemonia dos valores cristãos presentes também na política, que Maquiavel n’O Príncipe, escreveu acerca de como um governante deveria agir para construir uma nação forte e estável. Vale ressaltar que esta ação política descrita foi baseada por inteiro em experiências reais.

Para Maquiavel, não se tratava mais de enumerar as virtudes que o príncipe deveria ter para manter-se no poder, ao contrário do que pregava a moral cristã, ele afirma no capítulo XVIII d'O Príncipe que:

Não é necessário que um príncipe tenha de fato todas as qualidades acima enumeradas, mas é muito necessário que as aparente todas. Ousaria mesmo afirmar que possuí-las todas, e sempre as observar, chega a ser nocivo, mas aparentar possuí-las todas é útil. Assim é bom ser e parecer misericordioso, leal, humanitário, sincero e religioso; mas é preciso ter a capacidade de se converter aos atributos apostos, em caso de necessidade (MAQUIAVEL, 2000, p.103).

Por meio dessas palavras, pode-se cair no erro de compreender e diminuir o seu pensamento ao que pejorativamente diz-se "maquiavélico", assim como 
julgar que a máxima "os fins justificam os meios", possa significar que exista "na obra de Maquiavel a expressão de uma política voltada exclusivamente para seus fins" (BIGNOTTO, 1992, p.113). Todavia, vale dizer que o feito desta obra foi sistematizar as práticas dos detentores do poder, criando uma espécie de guia de governo, partindo da empiria. A ênfase imanentista dos seus estudos fez com que seu ponto de partida fosse a realidade concreta, ou seja, a verità effetuale, a verdade efetiva das coisas.

Ao centrar-se na análise sobre o Estado, Maquiavel substitui o dever ser da tradição cristã, pelo ser e agir. Sua ponderação política é orientada de forma que se possa descobrir "como pode ser resolvido o inevitável ciclo de estabilidade e caos" (SADEK, 2004, p.18) ao longo de um governo. Não se trata de estudar o tipo ideal de Estado, mas sim de analisar os modelos existentes. Foi desta mesma forma que realizou sua abordagem sobre o governante hábil para fundar e conduzir uma nação forte.

Gramsci (2000, p.14) afirma que, ao escrever O Príncipe, Maquiavel abordou como deveria ser o governante que conduziria o povo à fundação de um novo Estado. Para tanto, utilizou-se de todo um rigor lógico e científico. 0 último capítulo (XXVI), intitulado 'Exortação à libertação da Itália, dominada pelos Bárbaros', é uma reflexão sobre a conjuntura da Itália à sua época, onde de acordo com Gramsci, explicita-se mais claramente o verdadeiro sentido do livro, como sendo "algo similar a um manifesto político", transgredindo mais uma vez a soberania da Igreja e exaltando a importância da ação do povo para a unificação italiana:

A guerra é justa para aqueles a quem é necessária; e as armas são sagradas quando nelas reside a última esperança. É grande o nosso desejo; e não pode haver uma grande dificuldade onde há uma grande disposição de ânimo, desde que se siga o proceder daqueles que apontei como modelos. (...) Deus não fará tudo para não nos retirar o livre arbítrio e a parte de glória que nos cabe (MAQUIAVEL, 2000, p. 144).

Segundo Gramsci, O Príncipe de Maquiavel, como uma obra de cientificidade eminentemente política, poderia ser estudado como um manifesto de fato, ou seja:

Como uma exemplificação histórica (...) de uma ideologia política que se apresenta não como fria utopia nem como raciocínio doutrinário, mas como uma criação da fantasia concreta que atua sobre um povo disperso e 
pulverizado para despertar e organizar sua vontade coletiva (GRAMSCI, 2000, p. 13).

Por compreender a política de uma maneira inovadora, fundamentalmente a partir da ação humana ${ }^{2}$, a obra maquiaveliana deve ser considerada antes de tudo revolucionária. Possuidor de um estilo único, o autor não deve ser considerado mais um tratadista sistêmico da Idade Média e do Humanismo, ele vai além: seu estilo é o "de homem de ação, de quem quer induzir à ação; é estilo de 'manifesto' de partido" (GRAMSCI, 2000, p. 57).

Desta forma, Maquiavel não foi um moralista e nem se preocupou em redefinir valores, mesmo tendo atacado brutalmente algumas das crenças e valores que conformavam o núcleo da moral cristã. A sua oposição à religião católica se deu na medida em que ele a percebia como o principal impedimento para a unificação da Itália. Seu pensamento - rompendo com o "ideal" e operando com o "real" - deixa de perceber o mundo da política sob a ótica da divindade: agora, política se constrói fazendo. A ação humana passa a ter uma relevância jamais imaginada no universo teórico-político de sua época.

\section{O AGIR NA POLÍTICA: "VIRTú" VERSUS “FORTUNA"}

Na medida em que o pensamento de Maquiavel é balizado também pela importância da ação humana na construção e manutenção de um Estado, a política passa a ser compreendida como o resultado dos feixes de forças, provenientes das ações concretas dos homens em sociedade. Governar significa então, um equilíbrio de forças, e mais especificamente, a convivência e correlação entre a força do governante e a força do povo:

Quem chega ao poder com a ajuda dos ricos tem maior dificuldade em manter-se no governo do que quem é apoiado pelo povo. (...) De fato, o povo tem objetivos mais honestos do que a nobreza; esta quer oprimir enquanto 0 povo deseja apenas evitar a opressão (MAQUIAVEL, 2000, p.69-68).

É vislumbrando a política deste modo que Maquiavel, diante do fracionamento de seu país, dizia que somente um "bom" político poderia unificá-lo. Mas o que seria um "bom político" para o pensador? "Ser bom" para

\footnotetext{
${ }^{2}$ A política deixa de ser pensada como algo "contemplativo" e passa a ser compreendida muito mais como um constructo da ação humana já a partir do republicanismo renascentista (ou humanismo cívico) representado na Itália, por exemplo, por C. Salutati, L. Bruni, dentre outros.
} 
Maquiavel tem o mesmo significado do "ser bom" para a moral cristã? Para melhor responder e desenvolver essas questões, primeiramente faz-se necessário definir o que representa a virtú e a fortuna na lógica maquiaveliana.

De acordo com Maquiavel, somente um homem de virtudes - virtú - seria um bom político, melhor dizendo, seria capaz de fundar e manter um Estado forte e unificado. Ao contrário do que considerava a Igreja, a virtú maquiaveliana não estava em conformidade com a vontade divina, não se referia a uma porção de características pessoais que se restringiam ao âmbito da personalidade. Ao contrário, um bom governante deveria ser um homem capaz de grandes ações, capaz de intervir na realidade e saber quando e como deve aproveitar-se ou enfrentar as ocasiões. Segundo Moreira, para Maquiavel virtú seria:

(...) a qualidade do homem que o capacita a realizar grandes obras e feitos, 0 poder humano de efetuar mudanças e controlar eventos, é o pré-requisito da liderança, é a motivação interior, a força de vontade que induz aos homens, individualmente ou em grupo a enfrentar a fortuna (...) (1980, p. 13).

A fortuna, por sua vez, seria "o acaso, o curso da história, o destino cego, o fatalismo, a necessidade natural" (MOREIRA, 1980, p. 14). A ação política se desenrola, de acordo com Maquiavel, em torno de dois pólos, quais sejam: a virtú e a fortuna. Por sua vez, a ação é inerente ao cerne de seu pensamento e o homem de ação será o homem de virtú, capaz de dominar a fortuna. "No inicio do jogo, metade das ações dos homens é determinada pela fortuna e metade pela virtú. Maquiavel se propõe a mudar esse equilíbrio em favor da virtú" (idem).

No Capítulo XX d'O Príncipe, ao afirmar que "(...) a melhor fortaleza é a construída sobre a estima dos súditos, pois as fortificações não salvarão um príncipe odiado pelo povo" (MAQUIAVEL, 2000, p. 122), percebe-se que, a partir de então, o poder que tem seu fundamento na força é redefinido. Agora não se trata apenas da ação violenta, mas da sabedoria no uso da força, de sua utilização virtuosa. Sendo assim necessário virtú para se manter no poder.

De acordo com Moreira, ao concentrar sua atenção sobre as indicações "de como ganhar o poder, de como mantê-lo e por que se perde", nota-se que a preocupação principal de Maquiavel girava em torno da legitimação política entendida "como uma obediência tranqüila, consentida, que requeira um gasto mínimo do estoque, sempre limitado, das moedas do poder: força, propaganda, feitos externos, desempenho econômico" (1980,p. 20). Tal compreensão estratégica acerca do processo de legitimação política, vinda pelo povo, é explicitada no capítulo VIII d'O Príncipe: 
(...) ao tomar um Estado o conquistador deve praticar todas as necessárias crueldades ao mesmo tempo, evitando ter de repeti-las a cada dia; assim tranqüilizará o povo, sem fazer inovações, seduzindo-o depois com benefícios. (...) os benefícios por sua vez devem ser concedidos gradualmente, de forma que sejam melhor apreciados (MAQUIAVEL, 2000, p. 67).

Assim, a virtude tão necessária ao bom governante não se identifica com os valores morais cristãos, que eram acima de tudo abstratos. Trata-se justamente do oposto, pois está diretamente vinculado às possibilidades de ações concretas: 0 governante deve ter a sabedoria de agir conforme as circunstâncias, "não deixando fugir a occasione, a cabeça de ponte entre virtú e fortuna" (MOREIRA, 1980, p.14).

No capítulo IV d'O Príncipe, Maquiavel ressalta a importância que possui a occasione para o sucesso das ações dos governantes, afirmando que o êxito destes na batalha de conquista do poder depende sim de uma virtú, mas que independe do valor (moral) do conquistador: "(...) a dificuldade que outros enfrentam para manter suas conquistas (...) não dependia do valor maior ou menor dos conquistadores, mas da diversidade das condições, em cada caso" (MAQUIAVEL, 2000, p. 46).

A virtú maquiaveliana é espelhada nos grandes homens da Antigüidade que se mostraram capazes de construir governos fortes. 0 homem virtuoso, então, seria aquele corajoso, que conhecia e praticava a arte de guerrear sempre que necessário - vencendo a fortuna também pela força das armas. E assim, existe um elemento presente em toda a obra de Maquiavel: a adoção de Roma Antiga como parâmetro para a construção de um Estado italiano embasado na unidade política ${ }^{3}$.

Todo o pensamento maquiaveliano tem sido, muitas vezes, mal interpretado. Muitos estudiosos atribuem a Maquiavel a separação entre a ética e a política, afirmando que este princípio "maquiavélico" arraigou-se na modernidade dando margens à corrupção, à tirania e ao totalitarismo. Em meio a este debate, surge

\footnotetext{
${ }^{3}$ Vale ressaltar ainda que o pensador associa a virtude à masculinidade que, por sua vez, é vinculada à força, à coragem e à honra. A virtú em Maquiavel é derivada do latim "vir" - homem viril, bravo, guerreiro. Este posicionamento sexista é claramente explicitado quando diz: "Acredito seguramente que é melhor ser impetuoso do que cauteloso, pois a sorte é uma mulher, sendo necessário, para dominá-la, empregar a força; pode-se ver que ela se deixa vencer pelos que ousam, e não pelos que agem friamente. Como mulher, é sempre amiga dos jovens - mais bravos, menos cuidados, prontos a dominá-la com maior audácia" (MAQUIAVEL, 2000, p.141).
} 
como imperativo responder às seguintes questões: Mas o que seria ética? Será que pensar uma política que rompe com determinados valores morais de uma época denota necessariamente a ausência de ética?

\section{A POLÍTICA EM MaQUIAVEL: RUPTURA COM A ÉTICA?}

Ao definir o que é ética, Vázquez (2002) afirma que se deve ter bastante cuidado a fim de que não se confunda conceitualmente ética e moral, visto que são de fato coisas distintas:

Aéticaéa teoria ou ciênciado comportamento moral dos homensem sociedade. Ou seja, é ciência de uma forma especifica de comportamento humano. (...) A ética é a ciência da moral, isto é, de uma esfera do comportamento humano. Não se deve confundir aqui a teoria [ética] com o seu objeto: o mundo moral (VÁZQUEZ, 2002, p. 23).

0 autor diz ainda que a ética como teoria toma como ponto de partida um campo diverso de morais no tempo e no espaço. Sabendo que a palavra moral vem do latim mos ou mores, que significa "costume" ou "costumes", o "comportamento moral se refere assim, ao comportamento adquirido ou modo de ser conquistado pelo homem" (VÁZZUEZ, 2002, p.24), de maneira que os valores morais mudam de acordo com a sociedade e a época de que se trate.

A partir destes conceitos conclui-se, então, que 0 ataque maquiaveliano ao núcleo da moral cristã não significa que seu pensamento em torno da política seja desprovido de ética. Muito pelo contrário, este fundamentou toda a sua produção em torno de um "caráter" " distinto da sociedade de sua época: a ética do Antigo Império Romano. Neste aspecto, Maquiavel não realizou nenhuma manobra impossível, visto que a ética "como teoria, não se identifica com os princípios e normas de nenhuma moral em particular" (VÁZQUEZ, 2002, p.22).

0 que ocorre em Maquiavel então, não é a separação e oposição entre ética e política, de acordo com Bignotto ele apenas expõe e contrapõe dois tipos distintos de conceber a ética: "uma cristã, fundada na revelação e na consciência, e outra antiga, fundada no respeito ao bem público e às leis da pólis" (1992, p.06).

Berlin (2002) afirma que para Maquiavel a ética cristã não poderia promover um bom governo, sendo incapaz de fundar sociedades livres e fortes:

${ }^{4}$ Ética vem do grego ethos, que significa analogicamente "modo de ser" ou "caráter" enquanto forma de vida também adquirida ou conquistada pelo homem (VÁZZQUEZ, 2002, p.24). 
(...) os ideais do cristianismo são a caridade, a misericórdia, o sacrifício, o amor a Deus, o perdão aos inimigos, o desprezo pelos bens deste mundo, a fé na vida depois da morte, a crença na salvação da alma individual como algo de incomparável valor - mais elevado do que todo objetivo social, político ou qualquer outro propósito terrestre, qualquer outra consideração econômica, militar ou estética; na verdade, inteiramente incomensurável em relação a qualquer um desses valores. Maquiavel estabelece que, com homens que acreditam nesses ideais e os praticam, nenhuma comunidade satisfatória, no seu sentido romano, pode ser em princípio construída (BERLIN, 2002, p. 314315).

A ética antiga seria aquela coletiva, pública e do bem comum. Em que predomina o espaço público, seria a única capaz de beneficiar toda a nação. "A verdadeira ética nascia do contato dos homens com as exigências da vida pública e se conservava pelos costumes do povo" (BIGNOTTO, 1992, p.6).

Assim não se deve incriminar Maquiavel de ter instaurado um niilismo ético na política, pois conforme Bignotto, no momento em que este afirma categoricamente a superioridade da ética antiga sobre a de seu período, a discussão é mantida no terreno dos valores, ou seja, da moral. "É portanto, no universo de uma ética política, ou de uma política que carrega em si um corpo de valores diferentes daqueles de uma moral da consciência, que devemos buscar as fronteiras da ética" maquiaveliana (idem).

Em sua obra Discursos sobre a Primeira Década de Tito Livio (Discorsi), explicita-se claramente sua postura diante da religião cristã, contrapondo-a à antiga. Percebendo as religiões como construtos humanos, Maquiavel afirma que:

Nossa religião dá mais crédito às virtudes humildes e contemplativas do que à virtudes ativas. Nossa religião coloca a felicidade suprema na humildade, na abnegação, no desprezo das coisas humanas; a outra, ao contrário, considerava como bem soberano a grandeza da alma, a força corporal e todas as qualidades que tornam os homens temidos. Se a nossa exige alguma força de alma é para dispor-nos a sofrer, mais do que para que façamos alguma ação vigorosa (MAQUIAVEL, Discorsi, II,2 apud BIGNOTTO, 1992, p.6).

Segundo Chauí (2000), um dos pontos constituintes da ética dos antigos é a inseparabilidade entre ética e política ${ }^{5}$, não que não houvesse uma vasta

\footnotetext{
${ }^{5}$ Afirma Chauí (2000,p. 342) que aética antiga pode ser resumida em três aspectos: a racionalidade, pois se considera que ter uma vida virtuosa é agir de acordo com a razão, conhecedora do bem e do desejo, sendo capaz de guiar nossa vontade até se chegar aos objetivos almejados; o naturalismo,

NicColo Machiavelli: MORALISTA OU INTELECTUAL ORGÂNico? 
produção filosófica que definia separadamente o que significava cada um destes aspectos da vida humana. 0 que ocorre de fato, é que o pensar e o agir na política encontravam-se intrínsecos ao que seria ético para estas sociedades.

Foram os gregos e romanos que, na antiguidade, inventaram a política ${ }^{6}$. Tendo ambos em primeiro plano a vida pública, criaram suas leis a partir da vontade coletiva - votos, assembléias. A união entre ética e política para os antigos traduz-se na inseparabilidade também "entre a conduta do indivíduo e os valores da sociedade, pois somente na existência compartilhada com outros encontramos liberdade, justiça e felicidade" (2000, p.342).

A ética era concebida pelos povos antigos como "educação do sujeito moral para dominar racionalmente impulsos, apetites e desejos", orientando a vontade em direção ao bem e à felicidade, mas, principalmente, educar os homens e formá-los membros de uma coletividade sócio-política (idem). Já o cristianismo distancia-se dos valores da Antiguidade na medida em que:

Nasce como religião de indivíduos que não se definem por seu pertencimento a uma nação, mas por sua fé num mesmo e único Deus. Em outras palavras, enquanto nas demais religiões antigas a divindade se relacionava com a comunidade social e politicamente organizada, o Deus cristão relaciona-se diretamente com os indivíduos que nele crêem (CHAUÍ, 2000, p.343).

Deste modo, a fronteira da ética em Maquiavel é a ética pública, é a política, o agir político por excelência, em prol dos fins comuns. Essa ruptura traduz-se no fato de que o olhar sobre o campo da política não se dá mais a partir da moral do governante, mas sim por meio das relações de poder provenientes das ações humanas. 0 que mais importa, na realidade, é a qualidade das leis e das instituições. A política tem uma ética e uma lógica próprias, que se distingue das virtudes éticas do cristianismo. "Na ótica maquiaveliana, como na dos antigos, ética e política são faces de uma mesma realidade que não podem ser separadas" (BIGNOTTO, 1992, p. 8).

que afirma que a virtude no viver em conformidade com a Natureza (o cosmos) e com nossa natureza (nosso ethos), que é a parte de todo natural; e, por fim, a inseparabilidade entre ética e política.

${ }^{6}$ A palavra políticaé grega: ta politika, vinda depolis. Polis é a Cidade, entendida como comunidade organizada, formada pelos cidadãos (politikos), isto é, pelos homens nascidos no solo da Cidade, livres e iguais, portadores de direitos inquestionáveis, a isonomia (igualdade perante a lei) e a isegoria (o direito de expor e discutir em público opiniões sobre ações que a Cidade deve ou não deve realizar) (Chauí, 2000, p.371, grifos da autora). 
Percebe-se então, que ao atacar o modo cristão de pensar a política e a vida em sociedade, e adotando a ética-política antiga, Maquiavel respeitou a vontade coletiva e rejeitou o poder despótico. Em grego, despotes quer dizer "chefe de família" que representava uma autoridade incontestável no âmbito familiar, o poder privado (CHAUÍ, 2000, p.372). Sendo assim, ao abandonar a ética cristã, ele sobrepôs a importância da coisa pública - que pressupunha a política - em detrimento do privado que representa o despotismo.

A referência à importância que tinha a vontade do povo na política é uma constante na obra de Maquiavel. Ele percebia que seria impossível um governante se manter no poder somente pela força das armas, pela violência, vendo deste modo, a importância de um governo legítimo. Mesmo n'O Príncipe, considerado erroneamente como um manual direcionado aos "detentores do poder", a menção ao povo é uma constante em vários pontos da obra, como, por exemplo, no capítulo IX: "é necessário que o príncipe tenha o favor do povo; senão, não encontrará seu apoio na adversidade" (MAQUIAVEL, 2000, p.71).

De acordo com Gramsci (2000), Maquiavel foi na realidade "antimaquiavélico", visto que, compreendendo e desvendando como se dava o "jogo" da política, entregou-o muito mais ao povo do que propriamente aos governantes:

Pode-se assim supor que Maquiavel tenha em vista "quem não sabe", que ele pretenda promover a educação política de quem não sabe; não educação negativa, de quem odeia os tiranos, (...) mas positiva, de quem deve reconhecer como necessários determinados meios, ainda que próprios dos tiranos, porque deseja determinados fins (GRAMSCI, 2000, p. 58).

Mas que fins eram esses presentes insistentemente na obra maquiaveliana? A causa central de toda a sua obra é a questão da unificação italiana, a ponto de retomar o modelo Antigo e contrapor-se à hegemonia da Igreja, por vê-la como incapaz de tal feito. Neste sentido, Maquiavel teria sido e agido como um intelectual orgânico de sua época, teorizando em prol da construção de um novo Bloco Histórico: uma Itália unificada e soberana.

\section{CONSIDERAÇÕES FINAIS}

A obra de Nicolau Maquiavel é antes de tudo revolucionária. Na política, rompeu com os valores cristãos que minavam a sociedade italiana e favorecia a perpetuação de um Estado fragmentado e imerso na estagnação sócio-política e 
econômica. Assim, tudo o que ele produziu girava em torno de um objetivo central: a unidade política da Itália.

0 termo "maquiavélico", utilizado pejorativamente para classificar o governante totalitário, corrupto, dentre outros adjetivos, é derivado de uma compreensão errônea da obra deste pensador. Muitos teóricos e estudiosos da política - mesmo assumindo a importância do legado de Maquiavel, considerandoo fundador da Ciência Política - têm atribuído-lhe uma noção de política antiética, de ações voltadas exclusivamente para seus fins. De modo que, recai sobre o autor a culpa por ter construído os alicerces de uma política moderna ilegítima e violenta.

O Príncipe, considerado um manual direcionado aos governantes, além de ser um tratado teórico, deve ser entendido também como um manifesto político. Visto que teria servido muito mais para atacar de frente a hegemonia da Igreja, sugerindo e apontando caminhos ao povo rumo a uma ação política: a construção da unidade e da soberania italiana. A política pautada na moral cristã não conseguiria fundar um Estado livre e forte, pois esta se baseava em princípios abstratos, voltados para valores individuais e privados. Desta maneira Maquiavel retoma a ética da Antiguidade, na qual a ação humana ocupa lugar fundamental, tendo como cerne a vontade coletiva e o caráter público.

Os antigos percebiam a ética como intrínseca à política, e a política, por sua vez, pressupunha o público, a coletividade. Assim, o agir político maquiaveliano, longe de ser despótico e totalitário, estaria também balizado em instituições e leis fundamentadas na vontade coletiva, legitimadas pelo povo. Ao contrapor a ética cristã à antiga, Maquiavel estava atacando bruscamente a hegemonia da Igreja, considerada inábil para fundar e manter um Estado forte e unificado. E é desta forma que devemos compreender sua obra: como sendo voltada para a derrocada dos valores tradicionais de sua época, e para a fundação de um novo Estado, de novos valores em torno da vida política e em sociedade.

Melhor dizendo, o pensador não somente teorizou e sistematizou uma ciência política, ele produziu toda uma obra voltada para ação humana. E, ademais, este seria um agir político voltado para a construção de um novo Bloco Histórico - uma Itália unificada e fortificada.

Para tanto, naquele momento, elegeu como agentes políticos capazes de tal feito, os Médicis, a família que presidia a república de Florença: "não se vê, nesse momento, em quem mais ter a esperança que se ponha à frente (...) [da 
redenção italiana] senão a ilustre família Médici, exaltada pelo poder e pela sorte, favorecida por Deus e pela Igreja, que atualmente governa" (MAQUIAVEL, 2000, p.143). Maquiavel deve ser considerado não um moralista ou um niilista ético, mas um intelectual orgânico de seu tempo.

\section{REFERÊNCIAS}

BERLIN, Isaiah. A originalidade de Maquiavel. In: Estudos sobre a Humanidade: uma antologia de ensaios. São Paulo: Companhia das Letras, 2002, 299-348 p. BIGNOTTO, Newton. As fronteiras da ética: Maquiavel. In: NOVAES, Adauto. (org.) Ética. São Paulo: Companhia das Letras, 1992, 113-125 p.

Disponível em: http//:www.cefetsp.Br/Edu/eso/patrícia/fronteiraseticamaquiavel. html. Acesso: 02 fev. 2005.

CHAUÍ, Marilena. Convite à Filosofia. São Paulo: Editora Ática, 2000.

GRAMSCI, Antonio. Cadernos do Cárcere - Maquiavel notas sobre o Estado e a Política.vol. 3. Rio de Janeiro: Civilização Brasileira, 2000.

MAQUIAVEL, Nicolau. O Príncipe. São Paulo: Martin Claret, 2000.

MOREIRA, Marcílio Marques. 0 pensamento político de Maquiavel. In: 0 pensamento político de Maquiavel. Brasília: Editora Universidade de Brasília, 1980.

SADEK, Maria Tereza. Nicolau Maquiavel: o cidadão sem fortuna, o intelectual de virtú. In: WEFFORT, Francisco. (org.) Clássicos da Teoria Política. vol. 1. São Paulo: Editora Ática, 2004.

SCHMIDT, Mário Furley. Nova História Crítica: moderna e contemporânea. São Paulo: Editora Nova Geração, 1996.

VÁZQUEZ, Adolfo. S. Ética. Rio de Janeiro: Civilização Brasileira, 2002. 